\title{
The correlations between fall experience, balance, mobility and confidence in persons with stroke
}

\author{
Seokhwa Choi $\left.{ }^{\mathrm{a}(}\right)$, Byoung-Hee Lee ${ }^{\mathrm{b}(1)}$ \\ ${ }^{a}$ Choi Seokhwa Body Balance, Pocheon, Republic of Korea \\ ${ }^{b}$ Department of Physical Therapy, College of Health Science and Social Welfare, Sahmyook University, Seoul, Republic of Korea
}

Objective: This study conducted in order to investigate the correlations between fall experience, balance, mobility, and confidence. We examined the difference between fall experience, and Berg Balance Scale (BBS), Timed-Up-and-Go test (TUG), Tinetti balance assessment (Tinetti balance [TiB], Tinetti gait [TiG]), and Activities-specific Balance Confidence (ABC) scale scores to see how fall experience, balance, mobility, and confidence of the persons with stroke affects their balance.

Design: Cross-sectional study.

Methods: Forty-one subjects participated in this study. The BBS includes 14 items, consisting of a 5-point scale from 0 to 4 , totaling up to 56 points. The Timed Up and Go-Alone (TUGA) was used to measure the average time to take a $3 \mathrm{~m}$ round-trip by getting up and down from a 46-cm high chair with an armrest on a flat floor. The Timed-Up-and-Go-Cognitive (TUGC) was performed by counting backwards and the Timed Up and Go-Manual (TUGM) is performed by holding a cup full of water. The total score for the $\mathrm{TiB}$ is 16 points, and the TiG is 12 points, making a total of 28 points. There are 16 items total for the $\mathrm{ABC}$ scale.

Results: According to the fall experience, BBS, the TUGA and TUGC values were significantly higher in the inexperienced group compared to the experienced group $(p<0.05)$. The number of falls was significantly correlated with BBS, TUGA, TUGC, TUGM, TiB, TiG, TiB + TiG $(p<0.05)$.

Conclusions: This study supports that falls experience is strongly related to balance, mobility, and confidence. Optimal balance training programs for fall prevention is still insufficient and must be developed.

Key Words: Balance, Confidence, Fall experience, Mobility, Stroke

\section{Introduction}

Among the risk factors for stroke, the incidence of stroke has been decreasing due to the improvement and diagnosis of hypertension. However, in Korea, the incidence of stroke is increasing due to the Westernization of eating habits, the increase in the elderly population, the increase in risk factors, and the lack of treatment for causative diseases [1]. Edwards stated that loss of motor function leads to impaired motor control due to muscle weakness, abnormal muscle tension, and asymmetric movement patterns due to hemiplegia [2]. Balance greatly affects the performance of all exercises in everyday life and the ability to keep the body in equilibrium [3], balance when the body is moving, and the ability to keep the center of gravity constant within the base surface [4]. Gait is a complex exercise technique that is achieved through the interaction between the brain and the body, which quickly adapts to changes in situation and purpose, and must be supported by balance [5].

Because of poor balance, falls are one of the factors that threaten the health of the elderly, and falls are defined as unintentional contact with parts of the body with the floor and the center of gravity of the body is off the support [6]. Looking at the incidence of falls of more than once a year, approximately $30 \%$ of the population aged 65 years or older were reported to have fallen, and more than $40 \%$ of people

Received: 6 July, 2020 Revised: 10 August, 2020 Accepted: 17 August, 2020

Department of Physical Therapy, College of Health Science and Social Welfare, Sahmyook University, 815 Hwarang-ro, Nowon-gu, Seoul 01795, Republic of Korea Tel: 82-2-3399-1634 Fax: 82-2-3399-1639 E-mail: 3679@syu.ac.kr

(c) This is an Open-Access article distributed under the terms of the Creative Commons Attribution Non-Commercial License (http://creativecommons.org/licenses/ by-nc/4.0) which permits unrestricted non-commercial use, distribution, and reproduction in any medium, provided the original work is properly cited.

Copyright $@ 2020$ Korean Academy of Physical Therapy Rehabilitation Science 
over the age of 80 were reported. More than $40 \%$ of patients over the age of 65 who have experienced a fall suffer serious damage from fractures, bruises, soft tissue damage, etc., and $6 \%$ die after a fall [7].

Fifty to sixty percent of those who experienced a fall show fear of losing confidence or falling, and $25 \%$ to $33 \%$ of them are known to avoid activity because of this fear, and the mental trauma associated with falls is called post-fall syndrome [8]. Post-fall syndrome increases the fear complex, reduces confidence in normal daily living behaviors, decreases mobility, increases dependence and inactive lifestyle, which causes severe muscle atrophy of the lower extremity muscles $[7,8]$. However, fear of falls have also been reported in elderly people who have not experienced a fall event or related diseases [8]. Thus, regardless of whether or not there is a history of falls, older people who are afraid of falling tend to avoid physical activity [9], lose confidence in performing daily activities [10], and experience depression. Anxiety and the limited movement itself increase the risk of falls and ultimately have a direct impact on the quality of life of the elderly $[8,9]$.

The purpose of this study was to analyze the fall experience, balance, mobility, and confidence of patients with stroke by using the Berg balance scale (BBS), timed-up and go test (TUG), the Tinetti, and the activities-specific balance confidence (ABC) scale. The purpose of this study is to identify the effects of cognition and cognitive abilities on balance and to identify the need for fear management in order to treat falls within the stroke population.

\section{Methods}

\section{Participants}

This study was conducted on 41 patients who had been diagnosed with stroke and met the selection criteria after the announcement of the recruitment at the Choi Seok-hwa Body Balance Exercise Center. The subjects included in this study have been diagnosed with hemiplegia due to stroke, have been diagnosed for 3 weeks or more, have no visual or auditory defects, can stand for 1 minute without support, can walk more than $10 \mathrm{~m}$, and have a score of 24 or higher in Korean version of Mini-Mental State Examination. The subjects understood the purpose and agreed to participate in the study. The exclusion criteria were those did not meet the selection criteria and were unable to carry out the therapist's instructions, had perceived hearing loss, somatosensory defects affecting balance ability, and injuries that could affec standing posture balance. This study was deliberated and approved by the Institutional Review Board of Sahmyook University (IRB No. 2-1040781-A-N-01201915HR).

\section{Measurement tools}

\section{Berg balance scale}

BBS was developed by Berg in 1992 to assess the risk of falls in the elderly population [11]. Waking up from a sitting position, standing without holding, sitting without leaning on a back support, sitting in a standing position, moving between chairs, standing with eyes closed, standing with the feet close, holding the arms forward in a standing position, reaching out on the floor to pick up things, turn left and right, turn one wheel in place, place the feet alternately on the scaffold, stand with one foot in front of the other foot, and the single-leg stance. All 14 items consist of a 5-point scale, ranging from 0 to 4 , totaling up to 56 points [11]. In a study with patients affected by stroke, Liston reported that the test-retest reliability of the BBS was 0.98. The interdepartmental reliability was very high with a Spearman's rank-order correlation coefficient of 0.96 [12].

\section{Timed up and go test}

The TUG is a test method to measure functional mobility [13]. The intra-membrane reliability of this test was reported to be very high, with an intraclass correlation coefficient of 0.99 and an intraclass correlation coefficient of 0.99 among the elderly.

Based on Shymway-Cook [14], the TUG test was used in this study to measure the average time of taking a $3 \mathrm{~m}$ round-trip starting form a $46 \mathrm{~cm}$ high chair with an armrest placed on a flat floor. TUG was evaluated by dividing it into three states by adding the timed up and go-cognitive (TUGC) performed by counting the water upside down and the timed up and go-manual (TUGM) performed by holding a cup full of water.

\section{Tinetti balance assessment}

The Tinetti test is a tool that measures the risk of falls, balance, and mobility of the elderly. It consists of a balance test (Tinnetti balance, TiB) and a walking test (Tinetti gait, TiG). The balance test is 16 points, and the walking test is 12 points, making a total of 28 points. In general, if the score is 19 or less, the risk of falling is predicted to be high, and points 19-24 indicate a moderate risk of falling [15]. This study was used to evaluate the mobility of stroke survivors according to a previous study by Conesa et al. [16]. 
It is also an item that can identify typical walking patterns of individuals with stroke. Despite these facts, the research on the Tinetti-pedestrian scale has been mainly focused on Parkinson's disease and the elderly and is known to have high reliability with intra-class correlation coefficient $(\mathrm{ICC})=0.88-0.94$ [17]. A Tinetti-walking scale is a tool developed to assess mobility and fall risk in the elderly population [15].

\section{Activities-specific balance confidence scale}

The purpose of this study was to measure the self-confidence of the elderly using the $\mathrm{ABC}$ scale. There are 16 items in total, and each item has a score of 10 points ranging from 100 points for complete confidence to 0 points for complete anxiety. The score is the total score divided by 16 items and multiplied by 100 , which is a percentage $[8,18]$. Less than $50 \%$ is classified as low, $50 \%-80 \%$ as moderate, and $80 \%$ or greater as high level of functioning. In general, a low level of functioning is not possible for outdoor activities without assistance, a higher level of functioning is one with more than one chronic disease, and a high level of functioning indicates that the elderly is physically active [19]. Each of these items includes walking around the house, climbing up and down stairs, picking up slippers off the shoe rack, reaching out to pick up small items from the shelf at eye-level, reaching towards the toes and picking up overhead items, cleaning the floor, and ramp walking around the house in a car park, getting in and out of a car, walking to a shopping mall in a parked car, going up and down a ramp, walking in a crowded shopping street, walking in groups or bumping, walking up and down a railing, escalator, without holding a railing climb up and down, and walking outdoors on frozen sidewalks $[19,20]$. The reliability of the ABC scale is $\mathrm{ICC}=0.85$, which is high and reliable [21].

\section{Statistical analysis}

Statistical analysis was conducted using SPSS for Windows, Version 18.0 (IBM Co., Armonk, NY, USA). Fall experience, BBS, TUG, Tinetti and ABC correlations were examined using the Pearson's correlation coefficient. All statistical significance levels of the data were set to 0.05 .

\section{Results}

\section{General characteristics of subjects}

Table 1 shows the general characteristics of the patients with stroke included in this study.
Table 1. General characteristics of subjects $(\mathrm{N}=41)$

\begin{tabular}{llrl}
\hline \multicolumn{1}{c}{ Variable } & \multicolumn{1}{c}{ Division } & Frequency & Value \\
\hline Gender & Male & $26(63.4)$ \\
& Female & $15(36.6)$ \\
Age (y) & $30-39$ & $1(2.40)$ \\
& $40-49$ & $11(26.8)$ \\
& $50-59$ & $12(29.3)$ \\
& $60-69$ & $8(19.5)$ \\
& 70 over & $9(22.0)$ \\
Onset (mo) & $3-5$ & $10(24.4)$ \\
& $6-11$ & $18(43.9)$ \\
& $12-23$ & $11(26.8)$ \\
& 24 over & $2(4.90)$ \\
Diagnosis & Cerebral hemorrhage & $26(63.4)$ \\
& Cerebral infarction & $15(36.6)$ \\
Paralysis type & Right & $17(41.5)$ \\
& Left & $24(58.5)$ \\
Complications & Complications & $8(19.5)$ \\
& Not & $33(80.5)$ \\
Falls & Falls & $8(19.5)$ \\
& Not & $33(80.5)$ \\
Height (cm) & & & $165.73(8.76)$ \\
Weight (kg) & & $65.53(10.28)$ \\
\hline
\end{tabular}

Values are presented as $\mathrm{n}(\%)$ or mean (SD).

\section{Evaluation of balance, mobility and self-confidence}

Among balance, the BBS averaged 37.46 points, TUGA averaged 30.86 points, TUGC averaged 34.87 points, TUGM averaged 36.23 points, mobility TiB averaged 11.76 points, TiG averaged 7.22 points, Tinetti-Total (TiT) averaged 18.78 points, and the $\mathrm{ABC}$ of Balanced Confidence averaged 724.15 .

\section{Differences in balance, mobility, and self-confidence de- pending on fall experience}

Table 2 shows the data based on falls or no falls of the study subjects. There was a significant difference in BBS, TUGA, and TUGC scores according to the presence or absence of falls $(p<0.05)$.

Differences in balance, mobility, and confidence according to the type of paralysis

Table 3 shows the side of paralysis of the study subjects. There was a significant difference in BBS scores according to the area of paralysis, with an average of 33.29 in the right paralysis group and 40.42 in the left paralysis group $(p<0.05)$. 
Table 2. Falls or not falls

$(\mathrm{N}=41)$

\begin{tabular}{|c|c|c|c|c|}
\hline Division & Falls or no falls & Number & Value & $\mathrm{t}(p)$ \\
\hline \multirow[t]{2}{*}{ BBS (score) } & Falls & 26 & $34.50(11.25)$ & $-2.337(0.025)$ \\
\hline & No falls & 15 & $42.60(6.62)$ & \\
\hline \multirow[t]{2}{*}{ TUGA (m/s) } & Falls & 26 & $34.67(10.40)$ & $2.390(0.022)$ \\
\hline & No falls & 15 & $24.25(17.60)$ & \\
\hline \multirow[t]{2}{*}{ TUGC (m/s) } & Falls & 26 & $39.60(19.08)$ & $2.114(0.041)$ \\
\hline & No falls & 15 & $26.66(18.50)$ & \\
\hline \multirow[t]{2}{*}{ TUGM (m/s) } & Falls & 26 & $40.16(16.85)$ & $1.705(0.096)$ \\
\hline & No falls & 15 & $29.43(23.28)$ & \\
\hline \multirow[t]{2}{*}{ TiB (score) } & Falls & 26 & $11.46(4.04)$ & $-0.631(0.532)$ \\
\hline & No falls & 15 & $12.27(3.73)$ & \\
\hline \multirow[t]{2}{*}{ TiG (score) } & Falls & 26 & $6.88(2.96)$ & $-1.020(0.314)$ \\
\hline & No falls & 15 & $7.80(2.40)$ & \\
\hline \multirow[t]{2}{*}{ TiT (score) } & Falls & 26 & $18.04(6.12)$ & $-1.038(0.306)$ \\
\hline & No falls & 15 & $20.07(5.85)$ & \\
\hline \multirow[t]{2}{*}{ ABC scale (score) } & Falls & 26 & 674.23 (339.59) & $-1.116(0.251)$ \\
\hline & No falls & 15 & 810.67 (396.17) & \\
\hline
\end{tabular}

Values are presented as number only or mean (SD).

BBS: Berg balance scale, TUGA: timed up and go-alone, TUGC: timed up and go-cognitive, TUGM: timed up and go-manual, TiB: Tinettibalance, TiG: Tinetti-gait, TiT: Tinetti-total, ABC: activities specific balance confidence.

Table 3. Differences in balance, mobility, and confidence according to the type of paralysis

\begin{tabular}{|c|c|c|c|c|}
\hline Division & Paralysis type & Number & Value & $\mathrm{t}(p)$ \\
\hline \multirow[t]{2}{*}{ BBS (score) } & Right & 17 & $33.29(11.78)$ & $-2.074(0.045)$ \\
\hline & Left & 24 & $40.42(10.13)$ & \\
\hline \multirow[t]{2}{*}{ TUGA (m/s) } & Right & 17 & $34.98(14.48)$ & $1.593(0.119)$ \\
\hline & Left & 24 & $27.94(13.56)$ & \\
\hline \multirow[t]{2}{*}{ TUGC (m/s) } & Right & 17 & $38.37(14.45)$ & $0.958(0.344)$ \\
\hline & Left & 24 & $32.39(22.64)$ & \\
\hline \multirow[t]{2}{*}{ TUGM (m/s) } & Right & 17 & $41.79(18.16)$ & $1.532(0.134)$ \\
\hline & Left & 24 & $32.30(20.44)$ & \\
\hline \multirow[t]{2}{*}{ TiB (score) } & Right & 17 & $10.76(3.93)$ & $-1.384(0.174)$ \\
\hline & Left & 24 & $12.46(3.81)$ & \\
\hline \multirow[t]{2}{*}{ TiG (score) } & Right & 17 & $7.06(2.70)$ & $-0.309(0.759)$ \\
\hline & Left & 24 & $7.33(2.87)$ & \\
\hline \multirow[t]{2}{*}{ TiT (score) } & Right & 17 & $17.82(6.30)$ & $-0.852(0.399)$ \\
\hline & Left & 24 & $19.46(5.87)$ & \\
\hline \multirow[t]{2}{*}{ ABC scale (score) } & Right & 17 & $563.53(318.49)$ & $-2.546(0.015)$ \\
\hline & Left & 24 & $837.92(354.18)$ & \\
\hline
\end{tabular}

Values are presented as number only or mean (SD).

BBS: Berg balance scale, TUGA: timed up and go-alone, TUGC: timed up and go-cognitive, TUGM: timed up and go-manual, TiB: Tinettibalance, TiG: Tinetti-gait, TiT: Tinetti-total, ABC: activities specific balance confidence.

\section{Correlation coefficient between fall times, BBS, TUG, Ti, $\mathrm{ABC}$}

Table 4 shows the correlation between fall times, BBS, TUG, Ti, and ABC scores. Fall times showed statistically significant correlation with BBS, TUG, Tinetti, and ABC, respectively. 
Table 4. Correlation coefficient between fall times, BBS, TUG, Ti, ABC $(\mathrm{N}=41)$

\begin{tabular}{|c|c|c|c|c|c|c|c|c|}
\hline Division & Falls times & BBS & TUGA & TUGC & TUGM & $\mathrm{TiB}$ & $\mathrm{TiG}$ & TiT \\
\hline BBS (score) & $-0.455 * *$ & & & & & & & \\
\hline TUGA (m/s) & $0.446^{* *}$ & $0.793 * * *$ & & & & & & \\
\hline TUGC (m/s) & $0.384 *$ & $0.702 * * *$ & $0.870 * * *$ & & & & & \\
\hline TUGM (m/s) & $0.372 *$ & $0.720 * * *$ & $0.924 * * *$ & $0.969 * * *$ & & & & \\
\hline TiB (score) & $-0.364^{*}$ & $0.634 * * *$ & $0.667 * * *$ & $0.704 * * *$ & $0.698 * * *$ & & & \\
\hline TiG (score) & $-0.404 *$ & $0.710 * * *$ & $0.655 * * *$ & $0.640 * * *$ & $0.634 * * *$ & $0.699 * * *$ & & \\
\hline TiT (score) & $-0.422 *$ & $0.729 * * *$ & $0.712 * * *$ & $0.728 * * *$ & $0.724 * * *$ & $0.932 * * *$ & $0.836 * * *$ & \\
\hline ABC scale (score) & -0.053 & $0.705 * * *$ & $0.604^{* * *}$ & $0.567 * * *$ & $0.602 * * *$ & $0.408^{* * *}$ & $0.563 * * *$ & $0.464 * *$ \\
\hline
\end{tabular}

BBS: Berg balance scale, TUGA: timed up and go-alone, TUGC: timed up and go-cognitive, TUGM: timed up and go-manual, TiB: Tinetti-balance, TiG: Tinetti-gait, TiT: Tinetti-total, ABC: activities specific balance confidence.

${ }^{*} p<0.05,{ }^{* *} p<0.005,{ }^{* * *} p<0.001$.

\section{Discussion}

This study aimed to reduce the risk of falls and complications from falls by investigating the correlation between fall experience, mobility and self-confidence and discovering possible improvement factors early prior to the development of an intervention plan to prevent falls in stroke survivors.

According to a study by Hyndman et al. [22], of the 41 patients with stroke, 21 patients $(51.2 \%)$ had a fall experience, and 10 of them had repeated falls. As a result, it was reported that low upper extremity function $(p=0.018)$ and low daily living ability $(p=0.010)$, falls were experienced when standing up from a sitting position. A study by Ahn [23] compared functional performance according to the presence or absence of falls, and BBS scores showed a significant difference in the non-fall group $(p<0.001)$, as well as the TUG scores $(p<0.05)$.

In this study, among the 41 patients with stroke, 26 of the fall group and 15 of the non-fall group participated, indicating that $63.4 \%$ had a fall experience. Also, depending on the presence or absence of falls, there was a significant difference in BBS, TUGA, and TUGC scores in the non-fall group $(p<0.05)$. There was a difference in balance ability with or without falls. In the case of TUGM, moving a cup filled with water was added, which required more time for individuals with stroke with neurological damage. It appears that postural control ability in the fall group was lower than that in the non-fall group, and it seems that there was a difference between the two groups.

However, a previous study by Tinetii and Ginter [24] showed that a score of 19 or less had a high risk of falls, with a moderate risk of falls occurring between the score of 19 and 24. In this study, the TiT score was 18.04 points in the fall group and 20.07 points in the non-fall group, indicating that the risk of falls was high, but there was no statistically significant difference. This study investigated the correlation between fall experience and balance, mobility, and confidence of stroke survivors, and there was a significant difference in BBS and confidence scale scores according to the paralysis site. Through this, it is deemed necessary to improve fall management and confidence levels for patients with stroke.

\section{Conflict of Interest}

The authors declared no potential conflicts of interest with respect to the authorship and/or publication of this article.

\section{References}

1. Kim JY, Bae HJ, Park JM. Stroke statistics in Korea, 2018. Public Health Wkly Rep 2019;12:1845-60.

2. Edwards S. Neurological physiotherapy: a problem-solving approach. New York: Churchill Livingstone; 1996. p. 476-90.

3. Cohen H, Blatchly CA, Gombash LL. A study of the clinical test of sensory interaction and balance. Phys Ther 1993;73:346-51; discussion 351-4.

4. Nashner LM. Sensory, neuromuscular, and biomechanical contributions to human balance. Paper presented at: Balance: proceedings of the APTA Forum; 1989 Jun 13-15; Tennessee, United States. p. 5-12.

5. Capaday C. The special nature of human walking and its neural control. Trends Neurosci 2002;25:370-6.

6. Shumway-Cook A, Woollacott MH. Motor control: translating research into clinical practice. 3rd ed. Philadelphia: Lippincott Williams \& Wilkins; 2007. p. 387-422.

7. Lajoie Y, Gallagher SP. Predicting falls within the elderly community: comparison of postural sway, reaction time, the Berg balance scale and the Activities-specific Balance Confidence 
(ABC) scale for comparing fallers and non-fallers. Arch Gerontol Geriatr 2004;38:11-26.

8. Powell LE, Myers AM. The Activities-specific Balance Confidence (ABC) scale. J Gerontol A Biol Sci Med Sci 1995; 50A:M28-34.

9. Lach HW. Incidence and risk factors for developing fear of falling in older adults. Public Health Nurs 2005;22:45-52.

10. Lajoie Y, Girard A, Guay M. Comparison of the reaction time, the Berg Scale and the $\mathrm{ABC}$ in non-fallers and fallers. Arch Gerontol Geriatr 2002;35:215-25.

11. Berg KO, Wood-Dauphinee SL, Williams JI, Maki B. Measuring balance in the elderly: validation of an instrument. Can J Public Health 1992;83 Suppl 2:S7-11.

12. Liston RA, Brouwer BJ. Reliability and validity of measures obtained from stroke patients using the Balance Master. Arch Phys Med Rehabil 1996;77:425-30.

13. Podsiadlo D, Richardson S. The timed "Up \& Go": a test of basic functional mobility for frail elderly persons. J Am Geriatr Soc 1991;39:142-8.

14. Shumway-Cook A, Brauer S, Woollacott M. Predicting the probability for falls in community-dwelling older adults using the Timed Up \& Go test. Phys Ther 2000;80:896-903.

15. Tinetti ME. Performance-oriented assessment of mobility problems in elderly patients. J Am Geriatr Soc 1986;34:119-26.

16. Conesa L, Costa Ú, Morales E, Edwards DJ, Cortes M, León D, et al. An observational report of intensive robotic and manual gait training in sub-acute stroke. J Neuroeng Rehabil 2012;9:13.

17. Canbek J, Fulk G, Nof L, Echternach J. Test-retest reliability and construct validity of the tinetti performance-oriented mobility assessment in people with stroke. J Neurol Phys Ther 2013;37: 14-9.

18. Hawk C, Hyland JK, Rupert R, Colonvega M, Hall S. Assessment of balance and risk for falls in a sample of community-dwelling adults aged 65 and older. Chiropr Osteopat 2006;14: 3.

19. Myers AM, Fletcher PC, Myers AH, Sherk W. Discriminative and evaluative properties of the activities-specific balance confidence (ABC) scale. J Gerontol A Biol Sci Med Sci 1998;53: M287-94.

20. Miller WC, Deathe AB, Speechley M. Psychometric properties of the Activities-specific Balance Confidence Scale among individuals with a lower-limb amputation. Arch Phys Med Rehabil 2003;84:656-61.

21. Botner EM, Miller WC, Eng JJ. Measurement properties of the Activities-specific Balance Confidence Scale among individuals with stroke. Disabil Rehabil 2005;27:156-63.

22. Hyndman D, Ashburn A, Stack E. Fall events among people with stroke living in the community: circumstances of falls and characteristics of fallers. Arch Phys Med Rehabil 2002;83:165-70.

23. An SH, Lee BK. The relationships among fall down, self-efficacy and the functional performance ability in stroke patients. $\mathrm{J}$ Spec Educ Rehabil Sci 2011;50:269-88.

24. Tinetti ME, Ginter SF. Identifying mobility dysfunctions in elderly patients. Standard neuromuscular examination or direct assessment? JAMA 1988;259:1190-3. 